\title{
Peripheral osteoma on the medial eyebrow successfully extracted while preserving supratrochlear nerve
}

\author{
Ho Seup Sim, \\ Dong Gyu Lee, \\ Jae Ha Hwang, \\ Kwang Seog Kim, \\ Sam Yong Lee \\ Department of Plastic and \\ Reconstructive Surgery, Chonnam \\ National University Medical School, \\ Gwangju, Korea
}

\begin{abstract}
Osteomas are benign, slow-growing osteogenic lesions frequently found in the craniomaxillofacial region. They can be classified as peripheral, central, or extraskeletal. Reactive mechanisms to trauma or infection, as well as muscle traction, are thought to play a major role in the development of peripheral osteomas. In the present report, a 41-year-old woman presented with a slowgrowing, painless mass on her left eyebrow. She had suffered trauma 15 years prior. In the computed tomography scan, a $2.5 \times 2 \times 0.7-\mathrm{cm}$ radio-opaque tumor was detected just medial to the left supraorbital foramen, and a peripheral osteoma was clinically diagnosed. An elective operation under general anesthesia was planned. Following a suprabrow incision, subcutaneous and intramuscular dissection was performed. In the surgical plane deep to the corrugator muscles and superficial to periosteum, a branch of the supratrochlear nerve was encountered and preserved using a vessel loop. The osteoma beneath the periosteum was extracted in multiple fragments using a chisel and mallet to minimize trauma to the nerve. Contour and facial symmetry were corrected. To use a suprabrow incision, the surgeon must understand neighboring anatomical structures, including the course of the supratrochlear and supraorbital neurovascular bundles. When these structures are located adjacent to tumor lesions, careful surgical maneuvers should be performed to preserve them.
\end{abstract}

Keywords: Eyebrow / Forehead / Osteoma

\section{INTRODUCTION}

Osteomas are benign, slow-growing osteogenic tumors composed of mature compact or cancellous bone. They are most frequently found in the craniomaxillofacial region, especially in the mandible and paranasal sinuses [1,2].

Osteomas can be classified as peripheral, central, or extraskeletal. Specifically, peripheral osteomas are derived from the periosteum and are attached to the cortical plates while they grow.

\section{Correspondence: Jae Ha Hwang}

Department of Plastic and Reconstructive Surgery, Chonnam National University

Medical School, 42 Jebong-ro, Dong-gu, Gwangju 61469, Korea

E-mail: psjhhwang@daum.net

Received October 4, 2019 / Revised October 21, 2019 / Accepted October 22, 2019
Reactive mechanisms to trauma and infection, as well as muscle traction, are thought to play a major role in peripheral osteoma development [1,3-5].

Osteomas are usually diagnosed incidentally in radiological studies, as they are often asymptomatic and slow-growing [1,2]. However, various clinical signs may also manifest, depending on the size and location of the tumor. For example, when the tumor compresses the adjacent nerve, compressive neuropathy may develop. When osteomas occur in the forehead, facial asymmetry is the chief complaint [6]. In the present article, we report a case of a peripheral osteoma adjacent to the left supraorbital foramen, which was successfully extracted without jeopardizing the neighboring anatomical structures. 


\section{CASE REPORT}

A 41-year-old woman presented to the outpatient department seeking treatment for a painless mass on her left eyebrow (Fig. 1). She had no relevant medical history other than trauma that occurred 15 years prior: she had bumped her head. On physical examination, the mass measured $2.5 \times 2 \mathrm{~cm}$, and it was firm, round, and hardly movable. No cutaneous abnormalities were observed around the left eyebrow, and the patient reported no neurological symptoms such as sensory deficit.

A computed tomography (CT) scan revealed a $2.5 \times 2 \times 0.7-$ $\mathrm{cm}$ radio-opaque tumor just medial to the left supraorbital foramen (Fig. 2).

An elective operation under general anesthesia was planned. The patient's skin was incised horizontally along the wrinkle

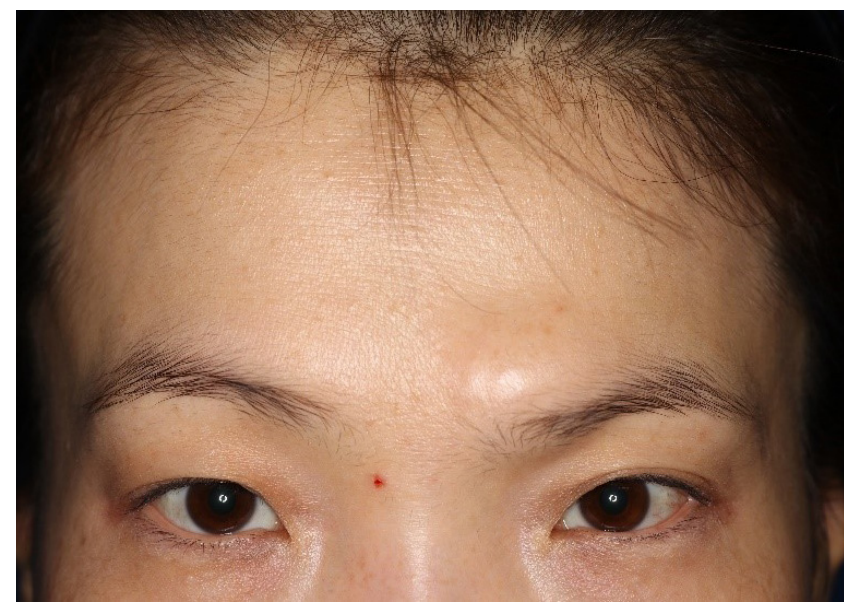

Fig. 1. A 41-year-old female patient presented with a slow-growing, painless mass on her left eyebrow. The mass was $2.5 \times 2 \mathrm{~cm}$ in size, firm, round, and hardly movable.

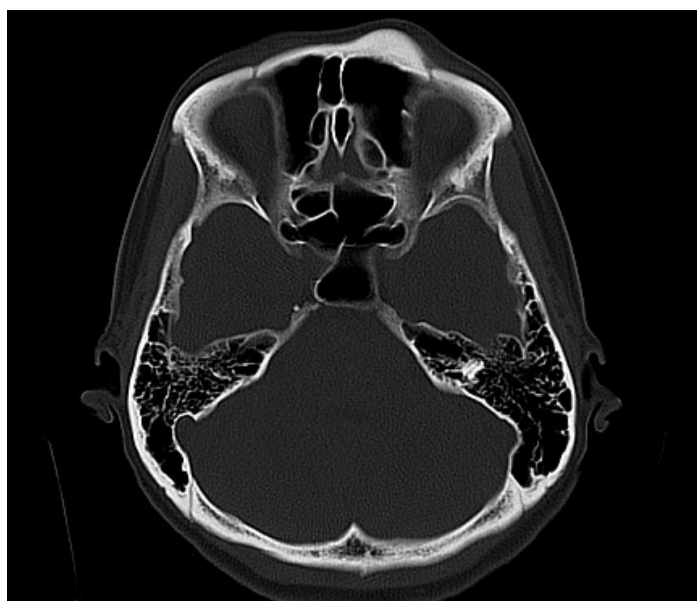

Fig. 2. In the preoperative computed tomography scan, a radioopaque lesion just medial to the left supraorbital foramen was observed. line, just above the hair-bearing area of the left eyebrow (suprabrow incision). The subcutaneous fat, as well as the frontalis and corrugator muscles, was dissected along the direction of the muscle fibers. In the surgical plane deep to the corrugator and superficial to the periosteum, a branch of the supratrochlear nerve was encountered; this was gently turned over using a vessel loop to the lateral aspect. A vertical incision was made in the periosteum, and a $2.5 \times 2-\mathrm{cm}$ osteoma was observed attached to the cortex of the frontal bone. Ostectomy was then performed using a chisel and mallet. The osteoma was extracted in multiple fragments to minimize trauma to the nerve. Contour was compared to that of the contralateral eyebrow and bilateral eyebrows were symmetrical. A postoperative CT scan showed that bone symmetry was adequately achieved (Fig. 3). Postoperative pathological findings were consistent with those

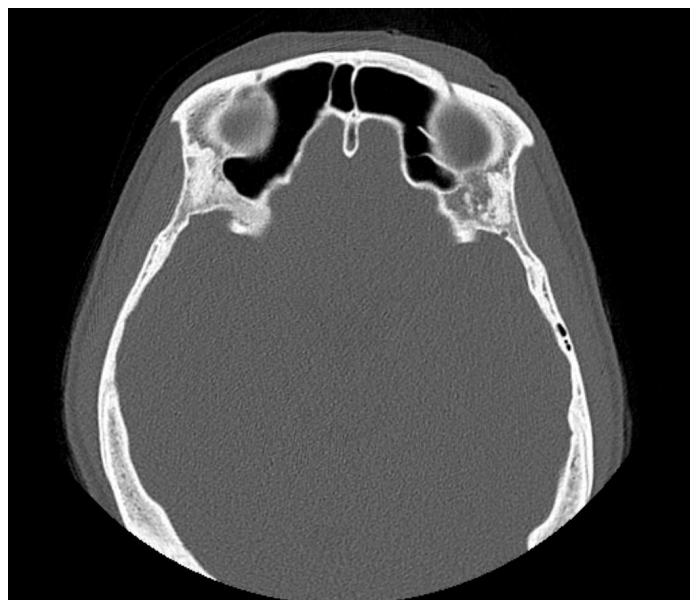

Fig. 3. In the postoperative computed tomography scan, the tumor lesion was removed and forehead symmetry was well achieved.

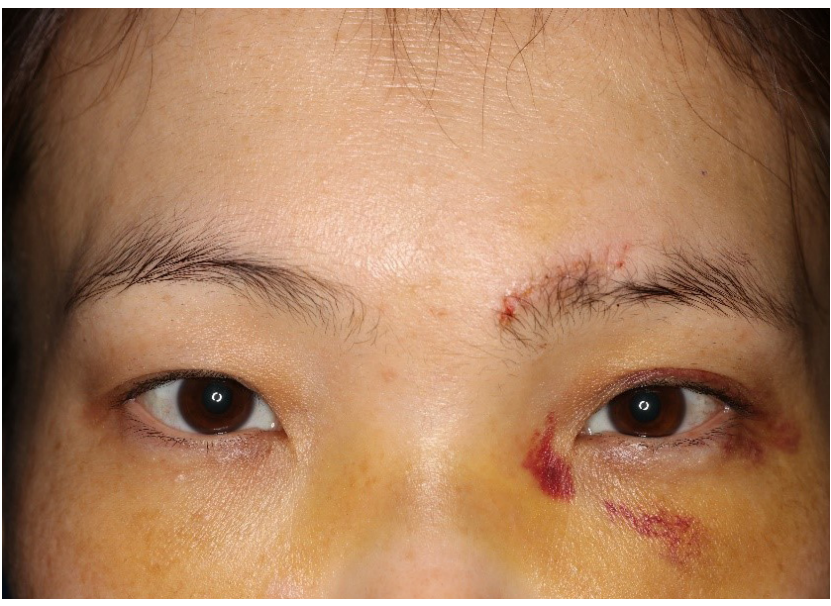

Fig. 4. Clinical photograph a week after the operation. Postoperative scars are well hidden, and the contours of the forehead are symmetrical. 
of an osteoma.

After surgery, no sensory deficit was observed. A clinical photograph was taken after 1 week and showed that the scar was well hidden (Fig. 4).

\section{DISCUSSION}

Osteomas are most frequently found in the craniomaxillofacial region, especially in the mandible and paranasal sinuses, and it occurs more often in men [1,2].

Osteomas are classified as peripheral, central, or extraskeletal. Central osteomas develop from the endosteum, while extraskeletal osteomas grow within a muscle. Meanwhile, peripheral osteomas are derived from the periosteum and are attached to the cortical plates while they grow. The etiology of osteomas is multifactorial, with traumatic, inflammatory, metaplastic, and genetic causes all playing a role [7]. In the case of peripheral osteomas, trauma and muscle traction are thought to play a major role in pathogenesis. Specifically, subperiosteal hematoma after trauma, combined with periosteal elevation caused by muscle traction, may result in osteogenesis [1,3-5].

Osteomas are slow-growing and often show no clinical symptoms. As such, they are usually incidentally diagnosed after radiological evaluations, and CT is the gold standard for diagnosis $[1,2]$. However, depending on the size or location of the tumor, various clinical signs may manifest. Facial pain or headache due to compression of the abutting sensory nerve is common [8]. Furthermore, obstructions to mucosal outflow can cause chronic sinusitis, while paranasal tumors extending into the orbital cavity can lead to ophthalmic symptoms, including epiphora, proptosis, diplopia, or visual loss. Osteomas can also result in auditory dysfunctions or intracranial complications, such as pneumocephalus or mucocele with intracranial extension [2,9]. Magnetic resonance imaging is helpful when evaluating intraorbital or intracranial extensions of the tumor [10]. In the case of osteomas located on the forehead, aesthetic deformities are the main complaint [6].

The supratrochlear nerve is a peripheral nerve that supplies sensation to the glabella, lower medial portion of the forehead, upper eyelid, and conjunctiva. The supratrochlear nerve exits into the deep tissues of the forehead and out of the frontal notch or foramen. The nerve runs between the periosteum and corrugator supercilii muscles. It then courses superficially to the muscle approximately $1.5 \mathrm{~cm}$ above the orbital rim [11]. Considering the anatomical plane the nerve runs in, when osteomas on the eyebrow are treated through a suprabrow incision, the intramuscular and periosteal plane should be dissected bluntly and vertically, parallel to the course of the nerves, and the tumor must be excised in the subperiosteal plane. In addition, during dissection, the surgeon must confirm the course of the nerve under direct visualization to avoid iatrogenic injury.

In cases of incidentally detected, asymptomatic osteomas, clinical observation is recommended. However, surgery is indicated if the tumor grows rapidly; if it involves the nasofrontal outflow tract, ethmoid sinus, or $>50 \%$ of the frontal sinus; or if it leads to symptoms, including aesthetic deformity [12]. In cases of forehead osteomas, open forehead ostectomy could be performed under direct visualization of the lesion. However, patients are often concerned about scarring, particularly those who have a smooth forehead or a genetic predisposition to hypertrophic scar, keloid, or skin pigmentation [6]. In such cases, incision through the hairline or eyebrow (suprabrow approach) may be preferable. Endoscopic resection of forehead osteomas is well established and avoids conspicuous scarring. However, potential complications include an increased risk of hematoma formation and significant postoperative edema $[6,13,14]$. Besides experienced practitioner and additional instruments are required in endoscopic approaches.

Osteomas are usually asymptomatic, except when they block or compress adjacent structures. In the eyebrow region, they can threaten the supratrochlear or supraorbital neurovascular bundles. To manage osteomas in this region, surgeons must understand the precise anatomy of the region and preserve these structures through meticulous surgical maneuvering.

\section{NOTES}

\section{Conflict of interest}

No potential conflict of interest relevant to this article was reported.

\section{Ethical approval}

The study was approved by the Institutional Review Board of Chonnam National University Hospital (IRB No. CNUHEXP-2019-266) and performed in accordance with the principles of the Declaration of Helsinki. Written informed consent was obtained.

\section{Patient consent}

The patient provided written informed consent for the publication and the use of her images.

\section{ORCID}

$\begin{array}{ll}\text { Ho Seup Sim } & \text { https://orcid.org/0000-0003-2911-0126 } \\ \text { Dong Gyu Lee } & \text { https://orcid.org/0000-0003-3701-0395 } \\ \text { Jae Ha Hwang } & \text { https://orcid.org/0000-0001-6992-8067 }\end{array}$ 
Kwang Seog Kim https://orcid.org/0000-0002-6766-4640

Sam Yong Lee https://orcid.org/0000-0002-3185-2519

\section{REFERENCES}

1. Boffano P, Roccia F, Campisi P, Gallesio C. Review of 43 osteomas of the craniomaxillofacial region. J Oral Maxillofac Surg 2012;70:1093-5.

2. Funieru C, Banica B, Cumpata CN, Sfeatcu RI, Dumitrache AM, Raescu M, et al. A rare case of osteoma in the frontal sinus: anatomical and histological description. Rom J Morphol Embryol 2014;55(2 Suppl):711-4.

3. Sayan NB, Ucok C, Karasu HA, Gunhan O. Peripheral osteoma of the oral and maxillofacial region: a study of 35 new cases. J Oral Maxillofac Surg 2002;60:1299-301.

4. Cutilli BJ, Quinn PD. Traumatically induced peripheral osteoma: report of a case. Oral Surg Oral Med Oral Pathol 1992;73: 667-9.

5. Kaplan I, Calderon S, Buchner A. Peripheral osteoma of the mandible: a study of 10 new cases and analysis of the literature. J Oral Maxillofac Surg 1994;52:467-70.

6. Meningaud JP, Toure G, Lantieri L. Endoscopic resection of osteoma of the forehead. Scand J Plast Reconstr Surg Hand Surg 2008;42:286-9.
7. Herford AS, Stoffella E, Tandon R. Osteomas involving the facial skeleton: a report of 2 cases and review of the literature. Oral Surg Oral Med Oral Pathol Oral Radiol 2013;115:e1-6.

8. Kaplan I, Nicolaou Z, Hatuel D, Calderon S. Solitary central osteoma of the jaws: a diagnostic dilemma. Oral Surg Oral Med Oral Pathol Oral Radiol Endod 2008;106:e22-9.

9. Ehieli E, Chu J, Gordin E, Pribitkin EA. Frontal sinus osteoma removal with the ultrasonic bone aspirator. Laryngoscope 2012;122:736-7.

10. Castelnuovo P, Valentini V, Giovannetti F, Bignami M, Cassoni A, Iannetti G. Osteomas of the maxillofacial district: endoscopic surgery versus open surgery. J Craniofac Surg 2008;19: 1446-52.

11. Janis JE, Hatef DA, Hagan R, Schaub T, Liu JH, Thakar H, et al. Anatomy of the supratrochlear nerve: implications for the surgical treatment of migraine headaches. Plast Reconstr Surg 2013;131:743-50.

12. Smith ME, Calcaterra TC. Frontal sinus osteoma. Ann Otol Rhinol Laryngol 1989;98:896-900.

13. Cronin ED, Ruiz-Razura A, Livingston CK, Katzen JT. Endoscopic approach for the resection of forehead masses. Plast Reconstr Surg 2000;105:2459-63.

14. Onishi K, Maruyama Y, Sawaizumi M. Endoscopic excision of forehead osteoma. J Craniofac Surg 1995;6:516-8. 